\title{
Overview of distributed energy storage for demand charge reduction
}

Said Al-Hallaj, CE0, AllCell Technologies, LLC, Chicago, Illinois 60609, USA, and Visiting Research Professor, Department of Chemical Engineering, University of Illinois at Chicago, Chicago, Illinois 60607, USA

Greg Wilk, Project Engineer, S\&C Electric Company, Chicago, Illinois, USA George Crabtree, Director of the Joint Center for Energy Storage Research, Argonne National Laboratory, Argonne, Illinois 60439, USA

Martin Eberhard, Founder of Tesla Motors and Serial Entrepreneur, Woodside, California, USA

Address all correspondence to Said Al-Hallaj at sahallaj@allcelltech.com

(Received 19 June 2017; accepted 13 December 2017)

\section{ABSTRACT}

The paper presents a comprehensive overview of electrical and thermal energy storage technologies but will focus on mid-size energy storage technologies for demand charge avoidance in commercial and industrial applications.

Utilities bill customers not only on energy use but peak power use since transmission costs are a function of power and not energy. Energy storage (ES) can deliver value to utility customers by leveling building demand and reducing demand charges. With increasing distributed energy generation and greater building demand variability, utilities have raised demand charges and are even including them in residential electricity bills. This article will present a comprehensive overview of electrical and thermal energy storage technologies but will focus on midsize energy storage technologies for demand charge avoidance in commercial and industrial applications. Of the ES technologies surveyed, lithium ion batteries deliver the highest value for demand charge reduction especially with systems that have larger power to energy ratios. Current lithium ion ES systems have payback periods below 5 years when deployed in markets with high demand charges.

Keywords: energy storage; energy generation; simulation

\section{DISCUSSION POINTS}

- What is the role of energy storage in renewable energy growth and grid stabilization?

- Energy storage technologies for smart grid applications.

- Economics of energy storage for demand charge applications.

- Grid-scale versus distributed energy storage. load generators like gas combined cycle $(\$ 61-\$ 87 / \mathrm{MW}$ h) or coal (\$66-\$151/MW h). ${ }^{3}$

Energy storage (ES) technology can charge during low demand periods and discharge during high demand periods to reduce peak electricity generation and therefore curtail new gas-peaking turbines and transmission equipment. When the utility installs ES technology it is referred to as 'in front of the meter ES' and when electricity customers install ES technology it is referred to as 'behind the meter ES'.

\section{In-front of the meter energy storage installations}

In front of the meter energy storage is relatively large in scale and project based. Traditional storage technologies include hydroelectric storage, compressed air storage, and lead acid battery storage. ${ }^{4}$ Pumped hydro storage accounts for $98 \%$ of US national energy storage capacity and works by pumping water from a low elevation reservoir to a higher reservoir to charge the system and then releasing the water through a turbine between the two reservoirs to discharge the system. ${ }^{5}$ Pumped hydro is economical when built into sites that already have 


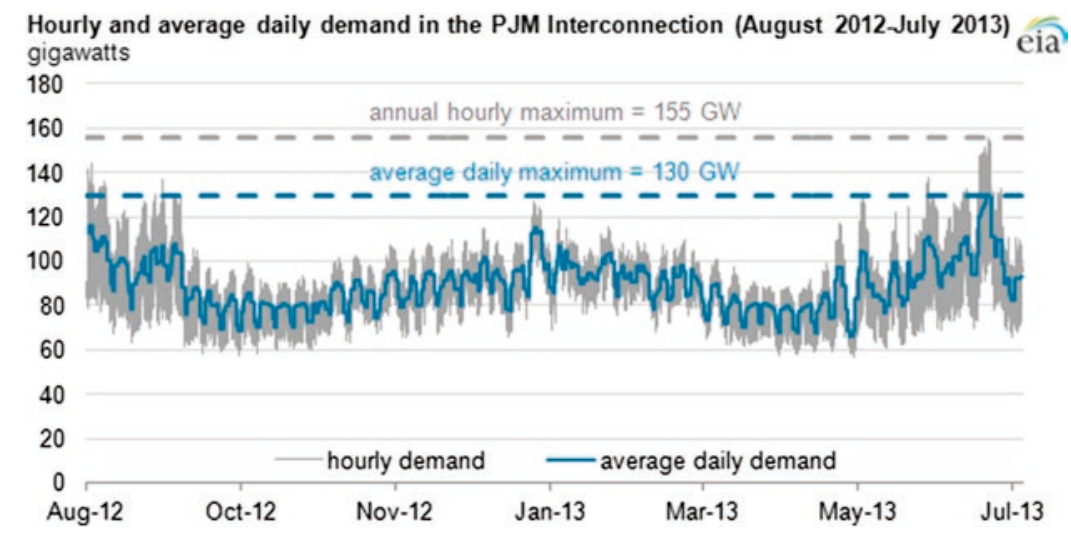

Figure 1. Hourly and average daily demand in the Eastern United States electricity transmission network: the PJM Interconnection (August 2012-July 2013). Generation and transmission equipment is built to handle the annual hourly maximum: $155 \mathrm{GW}$ while the majority of the year this equipment remains underutilized, Source: W. Booth, Energy Inf. Agency (September 2013). ${ }^{1}$

water elevation change and is usually built into existing hydroelectric dams. Compressed air storage works by compressing air into large, underground caverns and then releasing the highpressure air through a turbine when electricity is required. Energy storage installations provide value for the utility in price arbitrage and ancillary services. Price arbitrage is buying electricity when it is inexpensive, usually during the night, to charge storage systems and then discharge the device to sell electricity when it is more expensive. The value of price arbitrage depends on the storage efficiency, utility electricity prices, transmission costs, existing pumped storage capacity, and other factors. Researchers at the National renewable Energy Laboratory (NREL) calculated the arbitrage value at $35 \$ / \mathrm{kW}$ year. for a $300 \mathrm{MW}$ storage device with $75 \%$ roundtrip efficiency providing arbitrage for a Colorado utility. ${ }^{4}$ Other studies report energy arbitrage values that range from $\$ 37$ to $\$ 115 \$ / \mathrm{kW}$ year (Table 1 ).
Most energy storage devices cost too much to recoup costs from energy arbitrage alone and have greater value providing ancillary services for utilities. This value comes from contracted payments to reserve power capacity for transmission system compensations, peak turbine replacement, frequency regulation, distribution services, PV integration, and other services. ${ }^{3}$ NREL valued ES devices at $\$ 65 / \mathrm{kW}$ year when used to provide reserve power capacity and $\$ 109.8 / \mathrm{kW}$ year when used to regulate grid frequency. ${ }^{4}$ Other studies report values for ancillary services that range from $\$ 38$ to $\$ 248 / \mathrm{kW}$ year (Table 2 ).

\section{Behind the meter energy storage}

Distributed energy storage does not need to be purchased by the utility, but rather businesses and households can install energy storage and reduce monthly utility bills. Distributed energy storage technologies are located at businesses and homes and

Table 1. Value of energy arbitrage.

\begin{tabular}{l|c|c|l}
\hline \multicolumn{2}{l}{ Location } & Years evaluated & Annual value $(\$ / \mathrm{kW})$ \\
\hline $\begin{array}{c}\text { PJM (eastern United States } \\
\text { transmission grid) }\end{array}$ & $2002-2007$ & $\$ 60-\$ 115$ & $\begin{array}{c}12 \mathrm{~h}, 80 \% \text { efficient device. Range of efficiencies and } \\
\text { sizes evaluated. Also, considers price difference } \\
\text { suppression effect in a market setting using price/ } \\
\text { load relationships }\end{array}$ \\
\hline $\begin{array}{l}\text { NYISO (New York state } \\
\text { public utility) }\end{array}$ & $2001-2005$ & $\$ 87-\$ 240$ & $\begin{array}{l}10 \mathrm{~h}, 83 \% \text { efficient device. Range of efficiencies and } \\
\text { sizes evaluated }\end{array}$ \\
\hline USA & $1997-2001$ & $\$ 37-\$ 45$ & $80 \%$ efficient device. Evaluates IS0-NE, CAISO, PJM \\
\hline CA & 2003 & $\$ 49$ & $10 \mathrm{~h}, 90 \%$ efficient device \\
\hline CA & $2010-2011$ & $\$ 25-\$ 41$ & $4 \mathrm{~h}, 90 \%$ efficient device \\
\hline CA & 2011 & $\$ 46$ & $16 \mathrm{~h}, 75 \%$ efficient pumped storage device \\
\hline
\end{tabular}


Table 2. Value of ancillary services.

\begin{tabular}{|c|c|c|c|c|}
\hline Market evaluated & Location & Years evaluated & Annual value (\$/kW) & Assumptions \\
\hline \multirow[t]{3}{*}{ Regulation reserves } & NYISO ${ }^{7}$ & 2001-2005 & $\$ 163-\$ 248$ & $\cdots$ \\
\hline & USA ${ }^{9}$ & 2003-2006 & $\$ 236-\$ 429$ & PJM, NYISO, ERCOT, ISO-NE \\
\hline & $C A^{10}$ & 2010-2011 & $\$ 117-\$ 161$ & $\begin{array}{l}\text { Co-optimized arbitrage and regulation, } \\
\text { most value is derived from regulation }\end{array}$ \\
\hline Contingency reserves & $U S A^{9}$ & 2004-2005 & $\$ 66-\$ 149$ & PJM, NYISO, ERCOT, ISO-NE \\
\hline \multirow[t]{3}{*}{ Combined services } & $C A^{10}$ & 2010-2011 & $\$ 117-\$ 161$ & $\begin{array}{l}\text { Arbitrage and regulation, most value } \\
\text { is derived from regulation }\end{array}$ \\
\hline & $C A^{11}$ & 2011 & $\$ 62-\$ 75$ & $\begin{array}{l}\text { Arbitrage, regulation, and contingency. } \\
\text { Included operational constraints } \\
\text { of pumped storage }\end{array}$ \\
\hline & USA $^{12}$ & 2002-2010 & $\$ 38-\$ 180$ & $\begin{array}{l}\text { Arbitrage and contingency. Caiso, PJM, } \\
\text { NYISO, MISO }\end{array}$ \\
\hline
\end{tabular}

they must be deployable and efficient at small scale. Chemical energy storage (batteries) and thermal energy storage (phase change materials) are the dominant behind the meter energy storage technologies since mechanical energy storage technologies like pumped hydro and compressed air storage rely on large scales and specific geography (high water elevation, underground caverns) for high efficiency. Prices vary for customers based on energy used, power used, and time of use, providing value opportunity for energy storage devices to transfer grid energy demand to lower price times and avoid high power draws. The most common utility rate elements and their relative potential to drive behind the meter ES sales are shown in Table 3.

Energy and power are charged differently because they require different investments from the utility, even if the quantity of energy is the same between both cases. One $100 \mathrm{~W}$ bulb powered for $10 \mathrm{~h}$ uses the same energy as ten, $100 \mathrm{~W}$ bulbs powered for $1 \mathrm{~h}$ : $1000 \mathrm{~W}$ h. However, the second case requires greater utility investments in generating capacity and grid maintenance to be able to provide the higher power levels, $1000 \mathrm{~W}$, for one hour versus a much smaller load, $100 \mathrm{~W}$, for a longer time.

Demand charges are based on peak power, not energy, and therefore energy storage technologies have unique value potential for demand charge reduction since energy storage capital costs are a stronger function of energy stored than power delivered. For many building load profiles, it takes a relatively low amount of energy to reduce peak power levels since these peak power periods occur over a brief time. The following section presents example utility rate schedules and how demand charges can be reduced by energy storage technology. The next section reviews technologies utility customers can purchase to reduce demand charges including batteries and thermal energy storage (TES). The final section presents simulation results of lithium ion batteries and phase change cooling storage for reducing demand charges on real building load profiles.

\section{Utility demand charges}

\section{Demand charge rates}

Utilities have rate schedules for industrial, commercial, and some residential customers that incorporate both demand and energy charges. Demand and energy charges can have different pricing based on the season, time of use, and how much electricity that customer has already used. Energy charge is calculated by multiplying the energy use by the associated rate. For example, if an industrial plant consumed $10,000 \mathrm{~kW}$ h of electricity in July and energy is charged at $\$ 0.10 / \mathrm{kW} \mathrm{h}$, the energy charge for July is $\$ 1000$. If TOU energy rate structures were applicable, then the energy consumed at different periods would be charged at different prices. In contrast, demand charges are calculated based on the 15-min period with the highest energy use per month. For example, if an industrial plant's highest energy use in the month of July was $90,000 \mathrm{~kW}$ h from 3:00 p.m. to $3: 15$ p.m. on July 5 , the maximum demand is calculated by dividing the energy by $15 \mathrm{~min}$ or $900 \mathrm{~s}$ to give $100 \mathrm{~kW}$. If the utility demand charge is $\$ 30 / \mathrm{kW}$, that industrial customer is charged $\$ 30 / \mathrm{kW}$ times $100 \mathrm{~kW}$ to give a $\$ 3000$ demand charge for July. If TOU demand rate structures are applicable, then the customer will be billed the period demand charge based on when their maximum demand occurs.

Table 4 presents three example rate schedules for three different sized Southern California Edison (SCE) customers that includes demand and energy charges with time of use variable pricing.

For SCE, the facility demand charge applies always while the summer on-peak rate is an additional charge that applies from 
Table 3. Utility rate categories. ${ }^{13}$

\begin{tabular}{l|l|c} 
Rate element & \multicolumn{1}{c}{ Description } & Opportunity for storage \\
\hline Customer charge & Fixed monthly charge independent of energy use & None \\
\hline Energy charges & Rates based on energy consumption & Depends if time of use rates are employed \\
\hline Demand charges & $\begin{array}{l}\text { Charge for peak power (kW) usage. Typically calculated by the } \\
15-\text { min period with the greatest energy use in billing cycle }\end{array}$ & High \\
\hline Flat rates & $\begin{array}{l}\text { Fixed cost of electricity that does not vary except for fuel cost } \\
\text { adjustments and other fees }\end{array}$ & None \\
\hline Seasonal rates & Rate varies by season & Low \\
\hline Time of use rates & $\begin{array}{l}\text { TOU or time-of-day rate structures usually vary 2-4 times a day. } \\
\text { Typically, lower cost at night, higher cost during late afternoon }\end{array}$ & Medium \\
\hline Tiered or block rates & Rates that increase with increasing electricity use & High \\
\hline
\end{tabular}

Table 4. 2016 SCE electricity prices for industrial customers. ${ }^{14}$

\begin{tabular}{|c|c|c|c|c|c|}
\hline & \multicolumn{3}{|c|}{ Energy charge ( $\$ / \mathrm{kW}$ h) } & \multicolumn{2}{|c|}{ Demand charge $(\$ / \mathrm{kW})$} \\
\hline & On peak & Mid-peak & Off-peak & Facility & Summer on peak \\
\hline TOU-GS-2 (20-200 kW) & 0.103 & 0.070 & 0.052 & 15.44 & 15.42 \\
\hline TOU-GS-3 (200-500 kW) & 0.102 & 0.069 & 0.052 & 17.64 & 15.51 \\
\hline TOU-8 (>500 kW) & 0.086 & 0.065 & 0.051 & 18.35 & 16.73 \\
\hline
\end{tabular}

June to September from noon to 6 p.m. for a total demand charge $\sim \$ 30 / \mathrm{kW}$. A wider look at demand charges across utilities nationwide showed that SCE's demand charge, $\sim \$ 30 / \mathrm{kW}$ during summer on-peak hours, were anomalously high. Wang and Li found 204 utilities that offered TOU programs for industrial customers distributed among 44 states. They surveyed the largest utility (by number of customers) in each of the 44 states represented in the study and compiled their peak energy and demand charges. 34 of 44 states surveyed had demand charges with the median $\$ 10.83 / \mathrm{kW}$ and maximum $\$ 25.47 / \mathrm{kW}$ (Vermont). ${ }^{15}$ Demand charges vary based on building demand, utility, time of use, and other variables so aggregating all demand charges was challenging.

Residential customers have historically not been charged for demand because household electricity use did not vary significantly between homes. Appliances like televisions, washing machines, and lights were nearly universal and their use patterns consistent enough so that the demand cost to the utility could be incorporated into flat or tiered energy charges. However, increases in rooftop solar panels, electric cars, energy storage, and demand control software create greater variability between household demands that cannot be properly accounted for with flat rate energy charges. ${ }^{16}$ At least 13 utilities have offered rate plans with demand charges for residents and more demand charges are proposed (Fig. 2). ${ }^{16}$

\section{Demand charge reduction value}

Residential demand charges provide economic opportunity for peak shaving technologies (smart meters, batteries, and TES) to lower residents' utility bills. Figure 3 is a January load profile from a Texan residence that was selected from a database of $>100$ anonymized Texan households due to its relatively high differences between average load and peak demand. ${ }^{17}$ While the house used more power during the summer due to higher air conditioning load, the differences between peak and average load was greater in January than in July due to the air conditioning running most of the day.

The average power for the house was $2.56 \mathrm{~kW}$ with demand as high as $5.64 \mathrm{~kW}$ and as low as $0.86 \mathrm{~kW}$. Applying a demand charge of $\$ 10 / \mathrm{kW}-$ month, which is on the high end of residential 


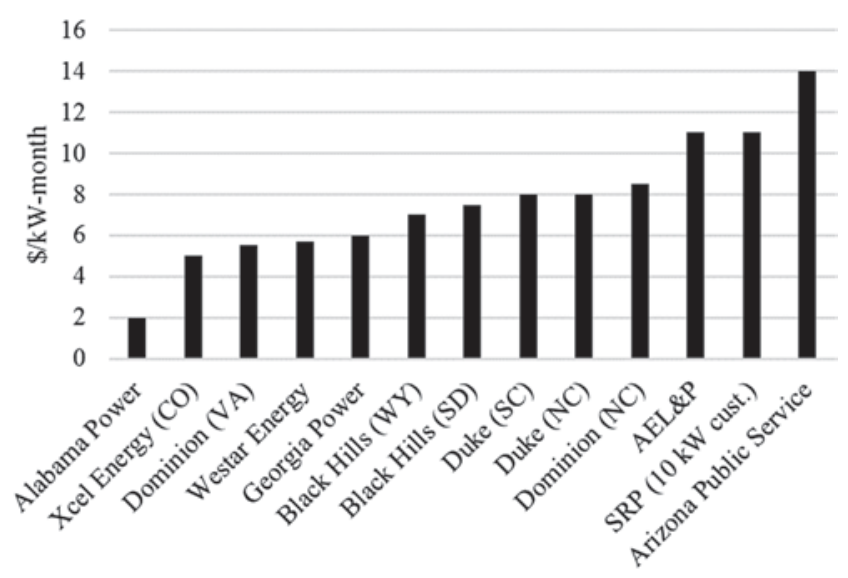

Figure 2. Summer demand charge for residential customers.

demand charges, this household would pay $\$ 56.40$ in demand charge for the month of January. Energy storage devices could level this demand by charging during low demand hours and discharging during peak demand hours. Assuming no change in energy consumption habits, the maximum possible reduction in demand charges was calculated by subtracting the average electric load from the peak electric load, which for the household in Fig. 3, was $3.08 \mathrm{~kW}$. Multiplying this reduction by the demand charge gave a potential utility bill reduction of $\$ 30.8$ for the month of January. This value is an upper, theoretical limit because the storage device would have to be $100 \%$ efficient and capable of matching the extreme load changes in time. Furthermore, an average Texan home would have a monthly demand charge closer to $\$ 20$, which is half that of the large home in Fig. 3 .

Commercial/industrial buildings have significantly greater demand charge reduction potential due to greater load variability and higher utility demand charges. Load data for commercial structures was acquired from EnerNOC's online database which anonymously published demand information, location, building size, and building type for 98 commercial facilities in $2012 .{ }^{18}$ Figure 4 shows the load profile for a large (1.67 million sq. $\mathrm{ft}$.) commercial building in Los Angeles during the month of July.

Applying SCE's summer on-peak demand charge for buildings over $500 \mathrm{~kW}, \$ 35.08 / \mathrm{kW}$-month, the maximum possible demand charge savings is $\$ 73,282$. A smaller, 48,878 sq. ft. grocer July load profile had a maximum demand charge reduction potential of $\$ 3753$.

Given the greater potential demand charge reduction opportunity for commercial/industrial installations, it is likely that behind the meter energy storage devices will have the greatest market penetration in large facilities. Residential demand charges are limited and the electric bill is a relatively small cost for most homeowners. The potential savings presented above are theoretical and require a $100 \%$ efficient energy storage device with large energy and power capacity to level the variable load. Real energy storage devices have lower efficiencies, limited power capacity, and ramp periods that cannot perfectly meet all demand peaks. The final section presents results from a more complicated NREL ES model that concludes which ES parameters are most important for demand charge reduction value.

\section{Current energy storage technologies for demand charge reduction}

\section{Energy storage parameters}

Current energy storage technologies marketed for demand charge reduction divide into two categories: chemical and thermal devices. Mechanical devices like pumped hydro and compressed air storage require specific geography and therefore are not relevant for utility customer demand charge reduction. Chemical devices are batteries that charge during low demand hours and discharge during peak periods to reduce peak demand. The two battery technologies investigated here are lead acid and lithium-ion. Future lithium ion battery chemistries are also

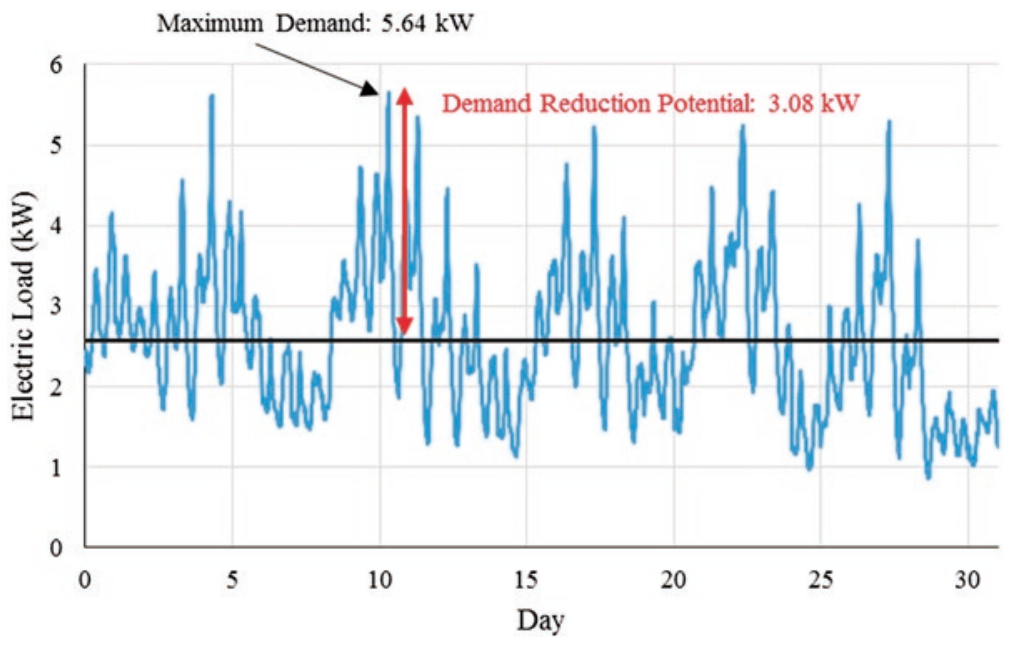

Figure 3. January load profile for a Texan house with high demand reduction potential. 


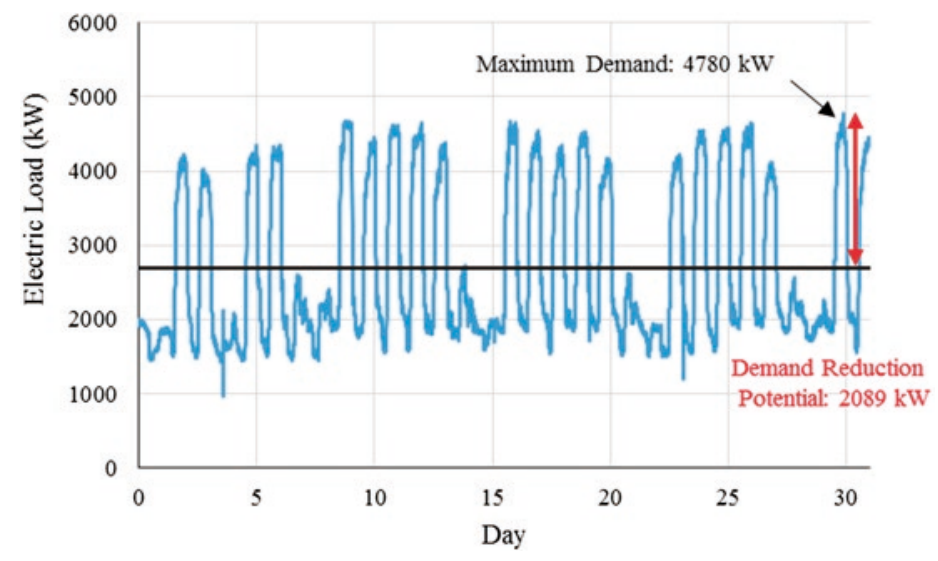

Figure 4. Large commercial business property July load profile.

discussed. Thermal devices work by heating or cooling an insulated medium during low demand periods and then providing heating or cooling capacity during peak demand periods to avoid using electricity from the grid. The thermal devices investigated here are water heaters, ice chillers, and phase change material (PCM).

Energy storage technologies were evaluated based on parameters listed in the following table with the units most relevant for behind the meter demand charge reduction listed (Table 5).

The value of energy storage technology for demand charge reduction is most sensitive to discharge time. Energy storage systems cost is primarily a function of the energy stored, or $\$ / \mathrm{kW}$ h. However, most building loads are parabolic in that increasing power use occurs over a decreased time period. ${ }^{17}$ Therefore, buildings require less energy to reduce the first $\mathrm{kW}$ of consumption than the second and so on etc. (Fig. 5).

System cost is proportional to both energy and power, while the demand charge reduction value is only proportional to power. Maximizing the power to energy ratio of the technology tends to minimize its payback period; however, there are limits. The energy storage system must have enough energy to meet the peak demand over it's entire duration. Furthermore, energy storage efficiency often decreases with larger power to energy ratios. The energy storage technologies currently available for demand charge reduction are detailed below with particular attention given to their discharge time, efficiencies, and capital cost.

Table 5. Energy storage device parameters.

\begin{tabular}{|c|c|c|}
\hline Parameter & Description & Relevant unit \\
\hline Power & The peak power the storage unit can deliver & kW \\
\hline Discharge time & How long it takes for the storage device to discharge all its energy & $\begin{array}{l}\text { C-rate or } 1 / \mathrm{h} \text {. A } 2 \text { C device discharges } \\
\text { completely in } 30 \text { min }\end{array}$ \\
\hline Self-discharge rate & How much energy is lost during periods of non-use & $\%$ over time \\
\hline Efficiency & $\begin{array}{l}\text { The ratio of the electrical energy discharged over the electrical } \\
\text { energy charged. For thermal devices where the energy output is } \\
\text { heat, the input electrical energy is first multiplied by the device } \\
\text { coefficient of performance before dividing by the thermal discharge }\end{array}$ & $\%$ \\
\hline Specific energy & This is the energy the device can store divided by its mass & $\mathrm{kW} \mathrm{h/kg}$ \\
\hline Specific power & This is the power the device can store divided by its mass & $\mathrm{kW} / \mathrm{kg}$ \\
\hline Lifetime & $\begin{array}{l}\text { How long the device can operate. ES devices usually do not fail } \\
\text { suddenly but rather decline in energy and power capacity over time }\end{array}$ & $\% /$ time \\
\hline
\end{tabular}




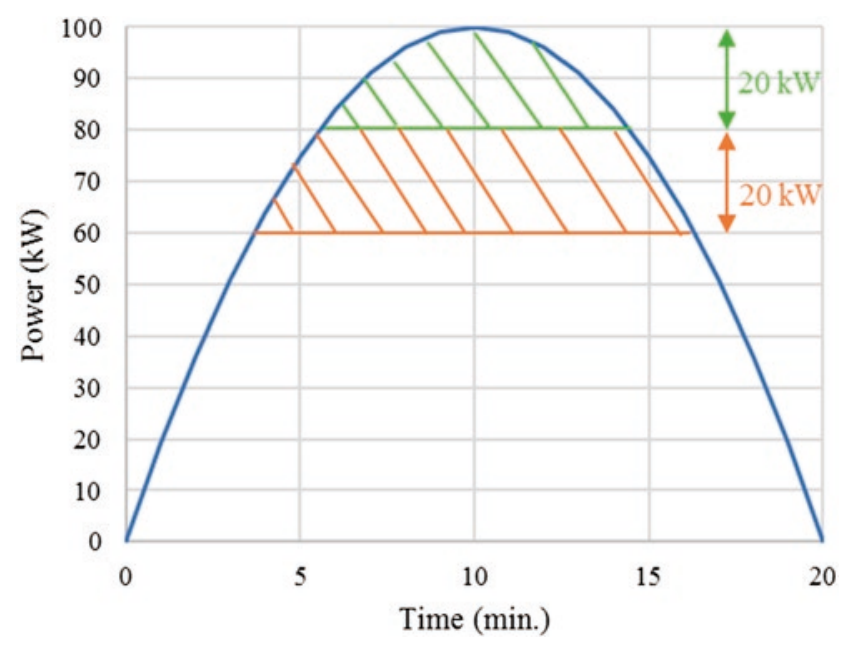

Figure 5. The energy required to reduce demand is the area under the power versus time curve. For parabolic demand profiles, reducing demand $20 \mathrm{~kW}$ requires less incremental energy than further reduction to $40 \mathrm{~kW}$.

\section{Battery system for demand charge reduction}

Batteries are charged during low electricity price periods from grid alternating current $(\mathrm{AC})$ which is converted to direct current (DC) using an inverter. During peak periods, batteries discharge to power electric loads by again passing through the DC-AC inverter (Fig. 6).

The battery bank can be of different cell types (lead acid, lithium ion, etc.) with each cell type having different discharge time, efficiency, specific energy, and cost. Inverters are largely agnostic with respect to battery cell type and thus are often cost estimated independently from battery cells. Inverters have conversion efficiencies that range from 95 to $99 \%{ }^{19}$ and typical balance of system costs for battery storage (inverter, containers, inter-connects, engineering, etc.) averages $\$ 670 / \mathrm{kW}$ with $41 \%$ cost reductions predicted by $2020 .{ }^{20}$ The battery storage roundtrip efficiency is less than the inverter efficiency because

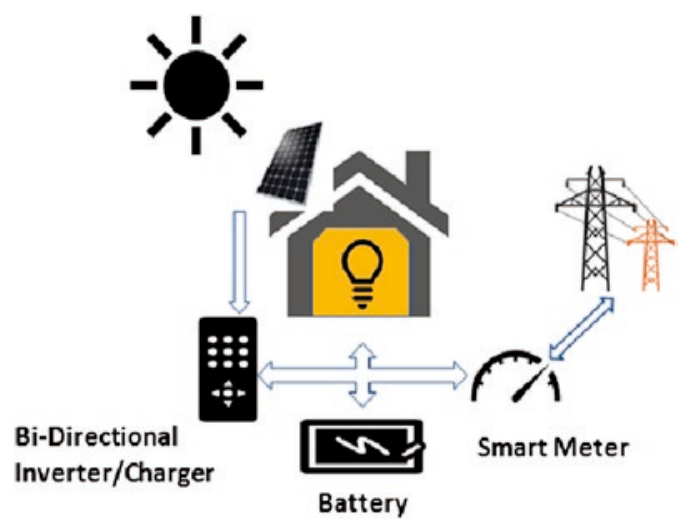

Figure 6. Battery system configuration for demand charge reduction. $\mathrm{PV}$ integration is also possible through a charge controller. power conversion happens twice: AC-DC when charging the battery and DC-AC when discharging the battery. Furthermore, batteries themselves are not $100 \%$ efficient and generate heat when charging/discharging. Studies on current battery energy storage systems cite roundtrip efficiencies from 83 to $89 \% .^{4,21-24}$ Battery cell cost scales largely with energy while inverter costs scale with power so systems with higher power to energy ratios generally cost more but bring greater value for demand charge reduction applications.

Therefore, it is important when discussing battery costs to distinguish between battery cell cost and balance of system costs. In addition, battery system costs can be normalized by power output or energy stored or a combination. For example, behind the meter battery costs simulated by NREL have an energy normalized price $(\$ / \mathrm{kW} h)$ and power normalized cost $(\$ / \mathrm{kW})$ that when multiplied by the system energy and power levels respectively are then summed for the full system cost. This full system cost can be divided by the system energy or power value to give a single energy or power normalized cost.

\section{Lead acid batteries}

Lead acid batteries have the longest history compared to other battery varieties. Lead acid cells work by submerging a lead dioxide cathode and lead anode in a sulfuric acid electrolyte bath. During discharge, both electrodes convert to lead sulfate while charging converts the electrodes back to lead as water in the electrolyte is broken down into gaseous hydrogen and oxygen. ${ }^{25}$

The main advantage of lead acid batteries for behind the meter energy storage is their low initial cost; however, lead acid batteries have poor efficiency at higher discharge rates $(60 \%$ at $1 \mathrm{C}$ rate). ${ }^{26}$ For demand charge reduction, where high power is more critical than high energy, lead acid batteries are a poor choice because systems must be large to achieve higher efficiencies, which negates the economic benefit of lower initial costs. Large lead acid battery installations produce significant concentrations of Hydrogen gas which can be a significant safety hazard for energy storage installations. ${ }^{27}$ Furthermore, lead acid batteries degrade significantly above $25^{\circ} \mathrm{C}$ and have reduced cycle life compared to lithium ion batteries. ${ }^{25,26}$ Most battery types, including lead acid cells, degrade quickly if fully discharged after every charge. Therefore, battery lifecycles are rated based on a set depth of discharge (DOD) or percentage the battery was drained after each charge cycle. Battery vendor Trojan sells a $100 \mathrm{~A} \mathrm{~h}$ lead acid battery for $\$ 224 / \mathrm{kW}$ h with a cycle life of 600 cycles at $80 \%$ (DOD). Dividing the energy normalized storage cost by the DOD (0.8) and cycle life (600) gives the battery lifecycle cost of $\$ 0.47 / \mathrm{kW} \mathrm{h}$, which is significantly higher than lithium ion cells $(\$ 0.29 / \mathrm{kW} \mathrm{h})$.

\section{Lithium ion batteries}

Lithium ion batteries have received a lot of research and commercial attention over the last decade and are in most portable electronics and electric vehicles. A lithium metal oxide cathode and a graphite anode are separated by an organic liquid 
electrolyte. ${ }^{25}$ Lithium has a low density, $534 \mathrm{~kg} / \mathrm{m}^{3}$, and a high electrode potential $(-3.04 \mathrm{~V})$, giving rise to large specific energy. ${ }^{28}$ Furthermore, Li-ion batteries have a longer cycle life that is more tolerant of greater DOD: 1900 cycles at 80\% DOD versus lead acid batteries that sustain 1000 cycles at 50\% DOD. ${ }^{26}$ Most relevant for demand charge reduction, Li-ion batteries have greater power capability than lead acid batteries: they can discharge fully in $1 \mathrm{~h}$ with $92 \%$ efficiency. ${ }^{26}$

Traditionally, the main disadvantage to lithium ion batteries were their higher cost. However, lithium-ion battery production is less mature than lead acid batteries and still cost $>\$ 300 / \mathrm{kW} \mathrm{h}$ compared with $\sim \$ 100 / \mathrm{kW}$ h for lead acid. ${ }^{26}$ However, prices have fallen dramatically in the last 10 years and further cost reductions are likely (Fig. 7).

Furthermore, lithium ion batteries can undergo greater charge-discharge cycles leading to a lower lifecycle cost compared to lead acid battery technology. Vendor AllCell Technologies quotes lithium ion batteries at $\$ 470 / \mathrm{kW}$ h with a 2000 cycle life at $80 \%$ DOD. Dividing the energy normalized storage cost by the DOD (0.8) and cycle life (2000) gives the battery lifecycle cost of $\$ 0.29 / \mathrm{kW} \mathrm{h}$, which is significantly less than lead acid batteries $(\$ 0.47 / \mathrm{kW} \mathrm{h})$ despite higher initial costs.

Lithium ion batteries differ primarily in their cathode chemistry creating tradeoffs in cost, specific energy, specific power, and safety. ${ }^{29}$ For most consumer electronics, $\mathrm{LiCO}_{2}$ (LCO) dominates due to their high energy density. ${ }^{30,31}$ However, $\mathrm{LiCO}_{2}$ batteries have relatively low specific power and life compared to other lithium ion chemistries. High specific power batteries include $\mathrm{LiFePO}_{4}$ (LFP) batteries as well as Lithium Titanate batteries (LTO). LFP batteries can have a long cycle life and moderate energy density; however, they exhibit greater selfdischarge which is a concern for energy storage applications. ${ }^{29,31}$ LTO batteries have poor energy density and high costs, but fast discharge times and long cycle lives. ${ }^{29}$ Toshiba sells a LTO battery called the SCiB with an advertised lifetime of 10,000 charge/discharge cycles and $80 \%$ capacity charge in 6 min. If costs decrease, such a battery could work well for demand charge reduction applications where power capacity is emphasized over energy capacity. ${ }^{32}$

Tesla is focused on two battery chemistries for electricity storage batteries: $\mathrm{LiNiCoAlO}_{2}$ (NCA) and $\mathrm{LiNiMnCoO}_{2}$ (NMC). ${ }^{33}$ Both chemistries can be tuned to favor a high energy density or

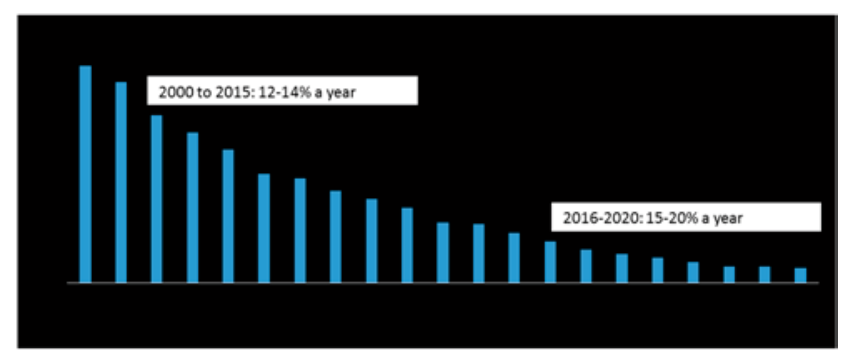

Figure 7. Lithium ion battery cost over time (Source: Benchmark Mineral Intelligence). power density based on the application. ${ }^{29}$ An NCA battery typically has a shorter cycle life, higher energy density, and higher power output than NMC batteries. Tesla envisions this battery chemistry replacing peak power generators that operate a few times a year at high power. An NMC battery generally has a longer cycle life, more stability, and less energy density. Tesla uses NMC batteries in their power wall installed in homes and businesses that cycle the battery daily. ${ }^{33}$ The battery chemistries discussed here are summarized in Table 6 .

Commercial integrated lithium ion battery systems exist including products from Tesla and LG that range in size from 3 to $10 \mathrm{~kW}$ h. Table 7 compares different battery storage options and their cost. It is important to note here that these costs and cost normalizations are for whole battery systems that include an inverter. Lithium ion cell costs are cheaper as shown in Fig. 7.

Tesla recently released higher power systems targeting commercial and industrial demand charge reduction market. A $100 \mathrm{~kW}$ h system that discharges in $2 \mathrm{~h}(\mathrm{C} / 2)$, has a total hardware cost of $\$ 60,550$ : $\$ 600 / \mathrm{kW} \mathrm{h}$ or $\$ 1200 / \mathrm{kW}$. LG markets even larger systems (1.68 MW h) for commercial demand charge reduction and frequency regulation with $>2 \mathrm{C}$ discharge rate (4 MW); however, price information is unavailable.

Lower discharge times compromise the safety of lithium-ion battery packs due to the increased risk of thermal runaway propagation. Thermal runaway can occur when a Li-cell reaches an abnormally elevated temperature either from a short circuit or de-stabilization of the cathode chemistry. The onset temperature for thermal runaway depends on the cathode chemistry and heating rate but ranges from 90 to $200{ }^{\circ} \mathrm{C}$. At these temperatures, unwanted exothermic chemical reactions begin to occur inside the cell. If the reaction heat generation is not dissipated, the cell temperature continues to climb, initiating more exothermic chemical reactions. This feedback loop can quickly escalate, resulting in peak cell temperatures more than $700{ }^{\circ} \mathrm{C}$ and the expulsion of superheated gases and flames. Additionally, the heat released from the failing cell can raise the temperature of surrounding cells in a module high enough to force them into a thermal runaway, as well, causing thermal runaway propagation. ${ }^{25}$

For Li-ion energy storage systems, a single cell in thermal runaway could quickly turn into thousands of cells in thermal runaway, creating an emergency. Such situations are not hypothetical, as illustrated by the battery fire that occurred in a Boeing 787 Dreamliner demonstrated in January 2013. ${ }^{34}$ Thermal runaway has also been identified in consumer electronics fires, including 6 Dell laptops utilizing Sony Li-ion cells that caught fire between 2005 and 2006. These fires prompted Dell to recall 4.2 million laptops and brought the issue of thermal runaway into the public spotlight. ${ }^{35}$

Li-ion energy storage systems use a combination of active and passive thermal management systems to ensure heat from a single cell in thermal runaway does not heat surrounding cells to thermal runaway conditions as well. Active thermal management systems use cooled air or liquid that circulates around battery cells to absorb generated heat. While active cooling can deliver relatively high cooling flux, energy is required for the safety system to operate. Passive cooling systems rely on the

8 - MRS ENERGY \& SUSTAINABILITY // VOLUME 5 // e2 // www.mrs.org/energy-sustainability-journal 
Table 6. Comparison between different lithium ion battery chemistries. ${ }^{29}$

\begin{tabular}{|c|c|c|c|c|c|}
\hline Battery chemistry & Specific energy (W h/kg) & Discharge (C-rate) & Cycle life & Relative cost & Comments \\
\hline LCO & $150-200$ & $<1 \mathrm{C}$ & $500-1000$ & Low & Common in consumer electronics \\
\hline LFP & $90-120$ & $1-3 \mathrm{C}$ & $1000-2000$ & Low & High self-discharge \\
\hline LTO & $70-80$ & $10 \mathrm{C}$ & $3000-7000$ & High & Safe \\
\hline NCA & $200-260$ & $1 \mathrm{C}$ & 500 & Moderate & Unstable \\
\hline NMC & $150-220$ & $0.7-1 \mathrm{C}$ & $1000-2000$ & Low & Growing market share \\
\hline
\end{tabular}

Table 7. Residential energy storage options.

\begin{tabular}{|c|c|c|c|c|c|}
\hline Model & $\begin{array}{l}\text { Energy storage } \\
\quad(\mathrm{kW} \mathrm{h})\end{array}$ & Power (kW) & Cost (\$) & $\begin{array}{l}\text { Normalized energy } \\
\text { cost }(\$ / \mathrm{kW} \mathrm{h})\end{array}$ & $\begin{array}{l}\text { Normalized power } \\
\text { cost }(\$ / \mathrm{kW})\end{array}$ \\
\hline Tesla powerwall 2 & 14 & 5 & 6500 & 465 & 1300 \\
\hline LG RESU6.5 & 6.5 & 4.6 & 4100 & 630 & 891 \\
\hline LG RESU10 & 9.8 & 7 & 5400 & 551 & 771 \\
\hline
\end{tabular}

thermal properties of the substrate holding Li-ion cells to dissipate generated heat. AllCell Technologies (Chicago, IL, USA) has pioneered the use of phase change materials (PCM) for cooling Li-ion batteries and has enhanced the PCM thermal conductivity by embedding it in a graphite matrix. The use of these PCM composites with Li-ion cells has been shown to be sufficient in managing the temperature rise of certain Li-ion batteries during transient operation. ${ }^{36}$ Graphite enhanced PCM materials have also been shown to arrest thermal runaway propagation in Li-ion battery packs. ${ }^{37}$

Lithium ion batteries have environmental impacts both in production and disposal. The United States EPA published a comprehensive life cycle assessment on lithium ion battery technology including $\mathrm{LiCoO}_{2}$ and $\mathrm{LiFePO}_{4}$ among other cathode chemistries. Cathodes containing cobalt and nickel metal require processing that can have adverse respiratory, pulmonary, and neurological effects in those exposed. ${ }^{38}$ Furthermore, the manufacturing of cathode materials is energy intensive and can be a global warming contributor if the energy used for production is nonrenewable. Finding secondary use for batteries and recycling materials can significantly reduce the battery life cycle impact. Companies focused on battery recycling exist with cobalt, copper, and nickel the most commonly recycled materials. ${ }^{39}$ With the tremendous sales growth of Li-ion batteries, economists have speculated on raw material scarcity. Most of the known supply of lithium is in Bolivia, Argentina, Chile, Australia, and China. ${ }^{40}$ The supply is ample and there is little concern of global shortages. Greater concern is placed in the availability of rare earth metals for different cathode chemistries as well as for the electric motors and magnets that will grow in conjuction with the Li-ion battery industry. However, battery research is extremely active and new chemistries are forecasted.

\section{Future lithium ion battery technology}

Initial lithium battery chemistry research focused on a pure lithium anode because its light weight and high chemical reactivity promised anodes with high theoretical charge storage capacity (3860 mA h/g). In 1977, Exxon found that on cycling, pure lithium anodes nucleate dendrites that grow across the electrolyte to the cathode and short circuit the battery, causing failure and the risk of fire. Despite this setback, researchers persisted with pure lithium anode chemistry in pursuit of high charge capacity and energy density. A long string of unsuccessful prototypes eventually forced a change from pure lithium to the current anode paradigm, intercalation of lithium ions in graphite and other carbon structures. These anodes can accommodate one Li for every six $\mathrm{C}$ atoms, leading to a significantly lower charge capacity, $372 \mathrm{~mA} \mathrm{h/g}$, compared to pure Li metal. The low Li capacity of graphite anodes fundamentally limits the energy density of today's Li-ion batteries (Fig. 8).

$\mathrm{Si}$ anodes offer an alternative to graphite, accommodating 4.4 Li ions for each $\mathrm{Si}$ atom for a theoretical charge capacity of $4200 \mathrm{~mA} \mathrm{~h} / \mathrm{g}$, slightly higher than for pure Li metal. ${ }^{41}$ Accepting so many Li ions implies a large volume expansion, over $400 \%$; this is the major challenge for $\mathrm{Si}$ anodes. The large volume change on cycling leads to fatigue and fracture of the anode, electrically 


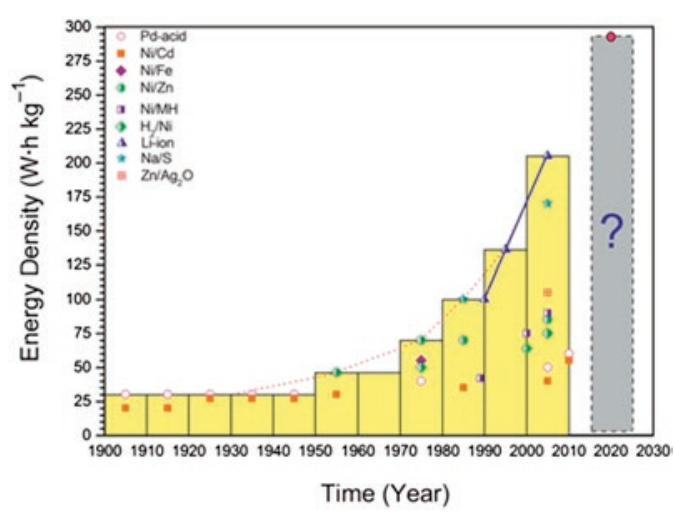

Figure 8. Secondary battery energy density over time. Lithium ion batteries are currently the most energy dense chemistry with substantial improvement possible by $2020 .{ }^{45}$

isolating the fragments that no longer participate in storing and releasing energy. The severe volume expansion can be accommodated without fracturing by nanostructuring in nanoparticles or nanowires, which have greater elastic range than bulk Si. Another approach is to mix Si with graphite in alloys or two phase composites, reducing the average expansion of the mixture to acceptable limits. Mixtures of order $5 \% \mathrm{Si}$ in graphite are in commercial development, giving incremental but important increases to energy density. Much larger Si content is envisioned as techniques are refined.

Replacing the organic liquid electrolyte in conventional Li-ion batteries with a solid-state electrolyte offers compelling advantages for energy density. The rigidity of a solid electrolyte can potentially block the growth of dendrites, allowing use of a pure Li metal anode. The challenge with solid state electrolytes is Li ion conductivity, often an order of magnitude lower than liquid organic electrolytes, severely limiting charge and discharge rates. The second challenge is grain boundaries in solid state electrolytes, offering penetration pathways for dendrites that often grow through the grain boundaries in the electrolyte to reach the cathode and short circuit the battery. Despite these challenges, the combination of Li metal anode and solid state electrolyte is a promising direction actively pursued by the community. ${ }^{42}$

The cathode offers opportunities for significant improvement in the energy density of Li-ion batteries. The most popular cathode, $\mathrm{Li}_{x} \mathrm{CoO}_{2}$, can reversibly intercalate Li over only half its range, limiting its practical capacity to $140-180 \mathrm{~mA} \mathrm{~h} / \mathrm{g}$, less than half the capacity of graphite anodes. ${ }^{22}$ Substituting some of the Co with other transition metals such as Ni or Mn allows incrementally higher voltage, capacity and energy density. Advances in these mixed transition metal oxide cathodes are the dominant direction in high energy density Li-ion batteries. ${ }^{43}$

Radical departures from the conventional Li-ion format, often called "beyond Li-ion batteries," offer opportunities for a step change in energy density. The most attractive departure is replacing the intercalation cathode with a conversion cathode, where Li forms a high energy covalent bond with the cathode atoms to create a new compound. Two of the most attractive conversion cathodes are oxygen with a theoretical battery energy density of approximately $3500 \mathrm{~W} \mathrm{h/g}$ and sulfur, with a theoretical battery energy density of $2567 \mathrm{~W}$ h/g. ${ }^{44}$ Early stage Li-S conversion batteries are now in production for niche markets, achieving approximately $10 \%$ of their theoretical energy density, while Li-O batteries are still at the research stage. These batteries, if developed to the point of mass commercialization, would dramatically transform the energy storage landscape for electric transportation and for a smart, decentralized electricity grid.

The different cell types-lead acid, lithium ion, and future lithium ion-are compared in Table 7 with the parameters most valuable for demand charge reduction applications. Reliability data for future lithium ion technology is unavailable and technical statistics are predictions.

\section{Thermal systems}

Thermal energy storage (TES) systems differ from batteries because they store energy as heat after electric power is consumed in an air conditioner or heater to change the temperature of a thermal storage medium. TES systems are not as flexible as battery storage because the stored energy can only be used for space heating/cooling; however, TES systems can have higher efficiencies and lower storage costs since thermal storage media are less expensive than chemical storage materials. While TES can only offset cooling and heating loads, there is market potential because space cooling accounts for $9 \%$ of total electricity sales and heating accounts for $25 \% .{ }^{47}$

TES cooling systems work by operating an air conditioning cycle to cool a storage medium: water, ice, or a phase-change material, during low demand periods and store this medium inside an insulated container. When cooling is required during high electricity demand periods, the cooled medium heat exchanges with building air to provide space cooling and avoid operating the air conditioner (Fig. 9).

Utilities, governments, and large building owners have long used TES cooling for specific applications and it is a relatively mature technology. Some specific projects include an 8.5 milliongallon chilled-water tank to cool Chicago's McCormick Place during the day and an ice storage system for the Pasadena Central Library and Civic Center. ${ }^{49}$ These civil projects are customized to the building size and usually require significant cooperation between the utility and site. Recently, there has been interest in developing smaller TES cooling units for commercial businesses and residences that are mass-produced and sold to building owners (Fig. 10).

In climates that have large daily diurnal temperature swings, TES systems can actually increase the AC efficiency because they can shift day time operation to the night where cooler ambient temperatures increase cycle efficiency. ${ }^{50,51}$ For example, the efficiency of air conditioning cooling systems using R-22 refrigerant degrades by $1.2 \%$ per degree above $95^{\circ} \mathrm{F}$ while R-410A, the refrigerant replacing R-22, degrades at $1.6 \%$ per degree above $95{ }^{\circ} \mathrm{F} .{ }^{50}$ Heat leakage through the storage container, heat exchangers, and piping make up most roundtrip 


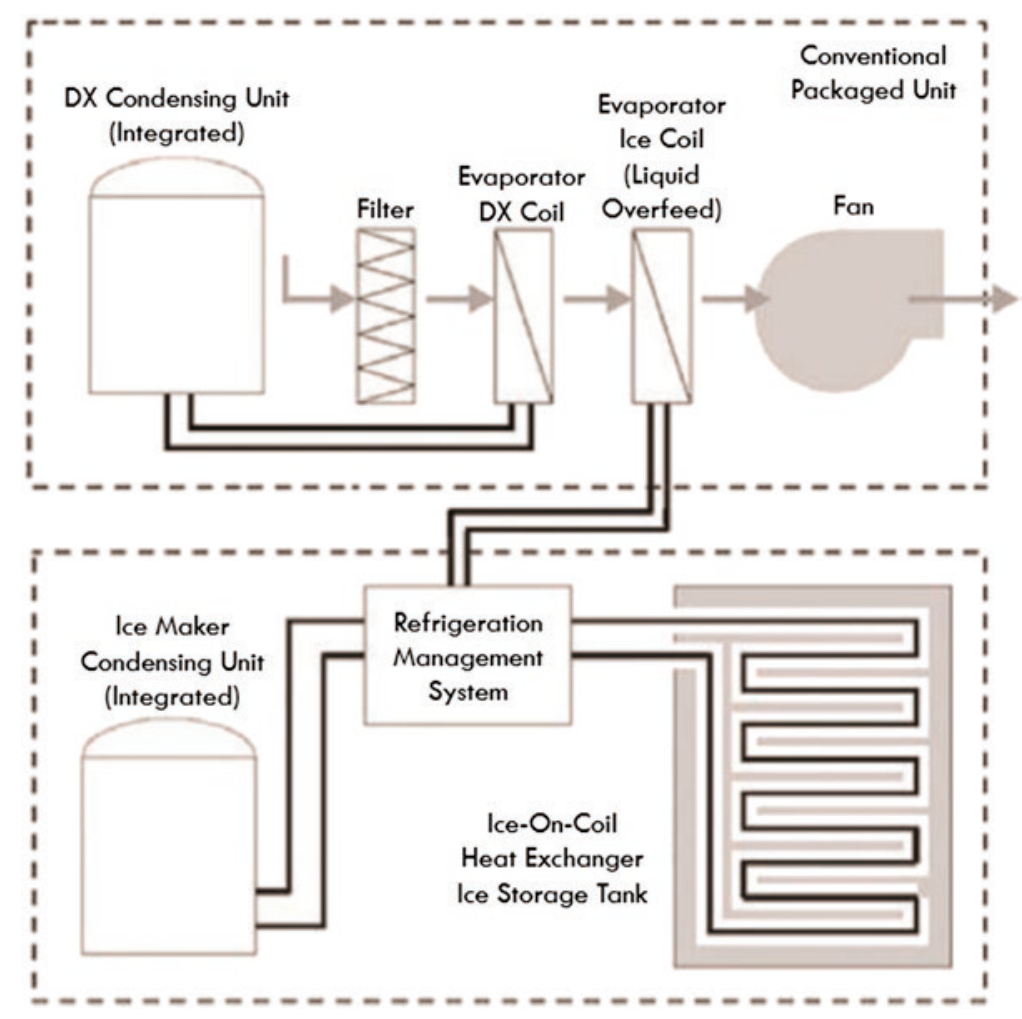

Figure 9. System configuration for an ice storage system operate in parallel with a direct expansion (DX) air conditioning cycle. During low demand periods, the icemaker works to cool a cycle fluid that freezes water in the ice storage tank. For demand charge avoidance, the pump cycles the fluid to the conventional evaporator to provide space cooling and avoid operation of the DX condensing unit. A phase change material with a higher melting temperature can replace ice and use the DX condensing unit for cooling. This eliminates the extra refrigeration cycle required for ice creation. ${ }^{48}$ CASHRAE www.ashrae.org. ASHRAE Transactions, (Vol 116), (Part 1), (2010).

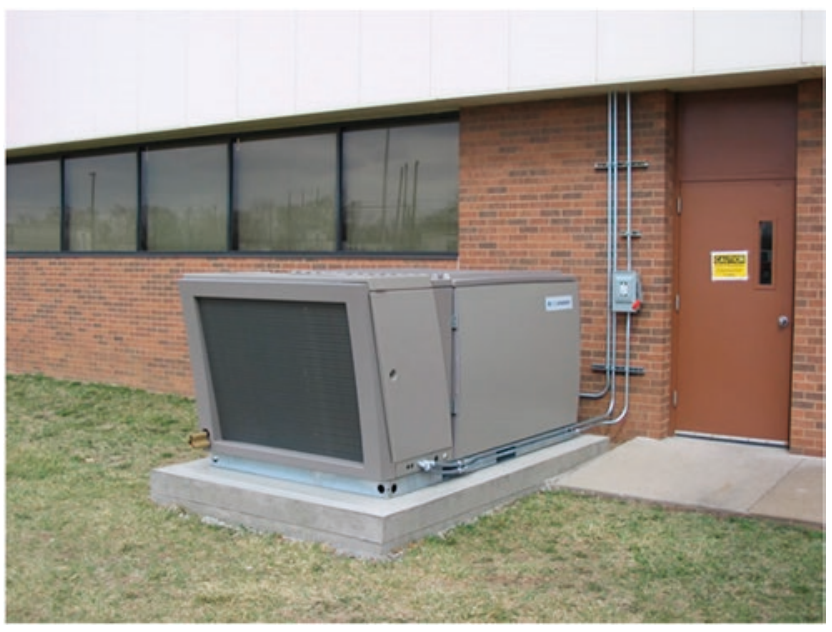

Figure 10. Ice Bear 30 Storage unit designed for distributed TES (Source: Ice Energy, reprinted with permission).

efficiency losses and can be limited through a greater use of insulating materials. The advantage over battery systems is a near $100 \%$ roundtrip efficiency conversion as the only losses for thermal energy stored is heat transfer through the insulating tank which can be inexpensively limited. ${ }^{52}$ Furthermore, there is little reduction in cycle life due to full discharge and charge cycling as the thermal medium does not chemically degrade during thermal cycling. The primary difference between TES cooling systems is the storage medium; ice and encapsulated wax are common and described below.

\section{Ice storage}

Ice storage operates a refrigeration cycle to cool water to its freezing point of $0{ }^{\circ} \mathrm{C}$ and take advantage of the high latent heat of water on freezing or melting, $93 \mathrm{~W} \mathrm{~h} / \mathrm{kg}$. Here it is important to note that the energy density is thermal energy and the input electrical energy is substantially less due to air conditioner thermodynamic efficiency. The storage medium, water, is effectively free; however, a second refrigeration cycle that operates at temperatures below standard air conditioning units is required to freeze water. ${ }^{53} \mathrm{~A}$ further challenge with ice systems is the low thermal conductivity of ice, $2.25 \mathrm{~W} / \mathrm{m} \mathrm{K}$, which limits the cooling power of ice storage devices. Shorter discharge times require greater quantity of expensive copper fins to transfer heat from the ice to discharging fluid. Vendor Ice Energy produces units that can offset up to $6 \mathrm{~h}$ of air conditioning cooling 
per day saving at maximum $40 \%$ on cooling bills. The energy density is high given the large latent heat of fusion of ice, $334 \mathrm{~kJ} / \mathrm{kg}$, but the discharge rate is limited to $\mathrm{C} / 3$ by the low thermal conductivity, $2.25 \mathrm{~W} / \mathrm{m} \mathrm{K}$, which must be enhanced with a high density of copper coils (Fig. 11).

Ice Bear uses a second refrigeration cycle for freezing ice that integrates with standard air conditioning units as shown in Fig. 12.

\section{Phase change materials}

Phase change materials other than water used for AC cooling include paraffin, fatty acids, and salt hydrates. ${ }^{44-47,54}$ Focusing on paraffin wax, the advantage over water is a higher melting temperature, $4-6{ }^{\circ} \mathrm{C}$; however, the latent heat of fusion is lower at $180 \mathrm{~J} / \mathrm{g}$ and the thermal conductivity is still low at $0.1-0.3 \mathrm{~W} / \mathrm{m} \mathrm{K}$. Paraffin wax can be encapsulated in a porous graphite structure to increase the thermal conductivity of the phase change composite material. ${ }^{55}$ AllCell Technologies manufactures a graphite wax composite that is $\mathbf{8 0 \%}$ paraffin wax by weight and has an in-plane bulk thermal conductivity of $\sim 20 \mathrm{~W} / \mathrm{m} \mathrm{K}$ and bulk latent heat of $\sim 150 \mathrm{~J} / \mathrm{g}$. The mass normalized storage capacity of the wax graphite composite is half that of ice; however, the increased thermal conductivity can reduce the quantity of copper necessary for fast discharge enabling system energy densities that equal ice systems. ${ }^{56}$

Due to the higher freezing temperature, wax TES can integrate directly with current AC cooling systems via a heat exchanger between the AC refrigerant and an ethylene glycol loop that runs through the wax composite material (Fig. 13).

This reduces system complexity and costs compared with ice storage systems.

\section{Hot water heating}

Hot water heating is another significant electric load for consumers and offsetting water heater operation to low demand periods can reduce demand charges. Utilities have identified electric water heater control as the least expensive current

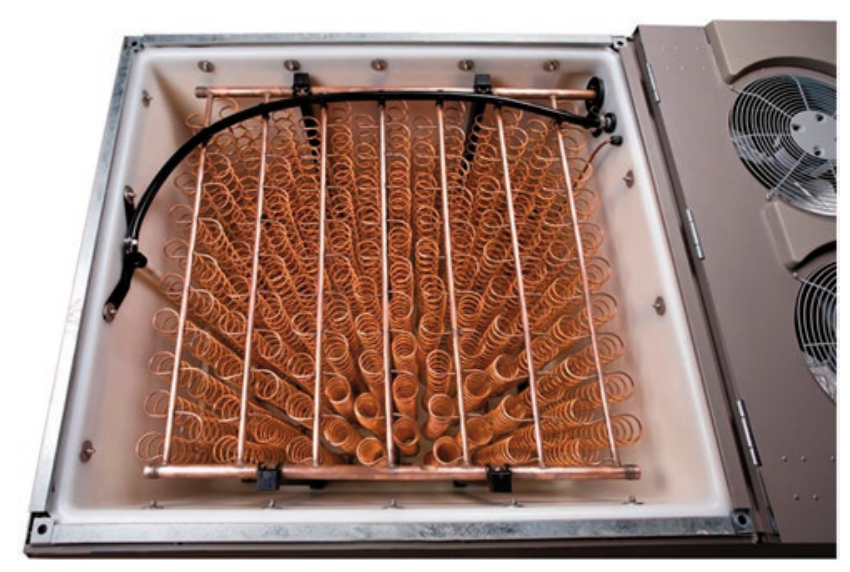

Figure 11. Ice Bear Ice Storage Compartment (Source: Ice Energy, reprinted with permission). energy storage solution ${ }^{57}$ with Sandia national labs estimating system installation cost at $\$ 110-\$ 300$ per $\mathrm{kW}$ of electric water heater power. ${ }^{58}$ The United States has about 45 million electric water heaters in service that demand $2-3 \mathrm{~kW}^{59}$ with most residential hot water usage in the morning and evening hours. ${ }^{51}$ A field study of controlling water heaters based on real time cost of electricity resulted in a $12.3 \%$ reduction in heating electricity cost with no reduction in user comfort. ${ }^{59}$ However, the report concluded that the utility must offer significant residential demand charges for the user to experience these savings. Commercial solutions exist either as entirely new water heaters with programmable controls or control systems that can be installed on current water heaters.

\section{Demand charge reduction simulation results}

The demand charge reduction value for a commercial or residential facility depends on the storage technology, utility rate, and load profile. Simulation is required to evaluate the annual utility bill savings based on these different parameters. NREL developed a tool called Battery Lifetime Analysis and Simulation Tool (BLAST) that combines a building electricity use profile, utility demand charges, and battery costs to output the optimum battery size for the highest internal rate of return (IRR). ${ }^{60}$ The IRR can be converted to total annual utility bill cost savings as well.

NREL simulated demand charge reduction potential for 98 different commercial buildings that range from small ( 2000 sq. ft.) food processing centers to large $(1,800,000 \mathrm{sq} . \mathrm{ft}$. shopping malls. ${ }^{61}$ The battery cost $\$ 300 / \mathrm{kW}$ and $\$ 300 / \mathrm{kW} \mathrm{h}$ added together based on the simulated energy and power size of the battery. Grouping the battery and inverter cost under a single power normalization overestimates costs when simulating over a range of power values since increasing system power is primarily a function of inverter size and not battery size. At higher C-rates above $1 \mathrm{C}$, the batteries need to be upgraded to handle the larger power output so a more accurate simulation would have a power normalized cost that varies with system power. NREL used the rate structure from Southern California Edison's TOU-GS-2 option B structure circa 2013 with similar time related costs to the 2016 rate structure detailed in Table 3 with summer on peak demand charges total $\$ 30.14 / \mathrm{kW}$. Each building load was simulated with 35 different battery storage sizes: seven energy levels, each with five different power levels (Table 8). The energy capacity of the battery systems was set as a percentage of the building maximum demand charge reduction or the energy required to level the building load assuming an ideal storage device (infinite power, 100\% conversion efficiency).

\section{Simulation results}

All 98-load cases showed the cost reductions due to demand charge reduction exceeded the cost reductions due to energy arbitrage by one to two orders of magnitude (Fig. 14).

The payback period for battery systems with the lower system duration (30 min or $2 \mathrm{C}$ rate) was about half that of systems with 


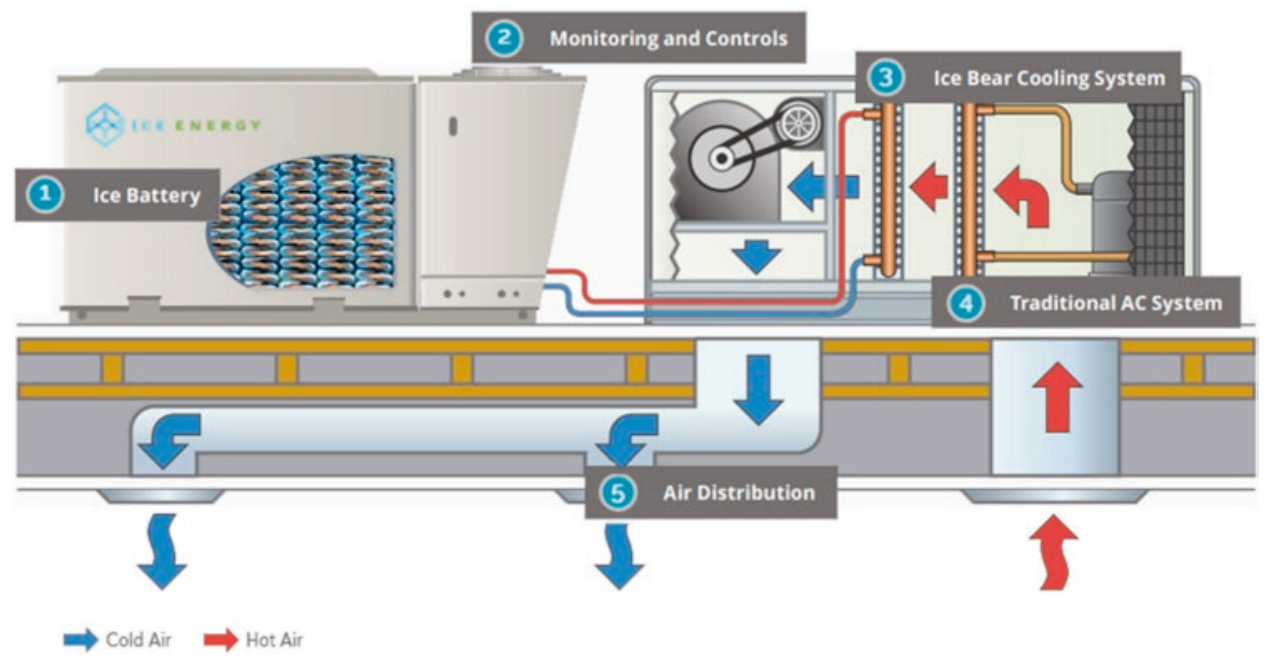

Figure 12. Ice Bear system configuration. Separate refrigeration cycles for ice generation (3) and normal air conditioning (4) (Source: Ice Energy, reprinted with permission).

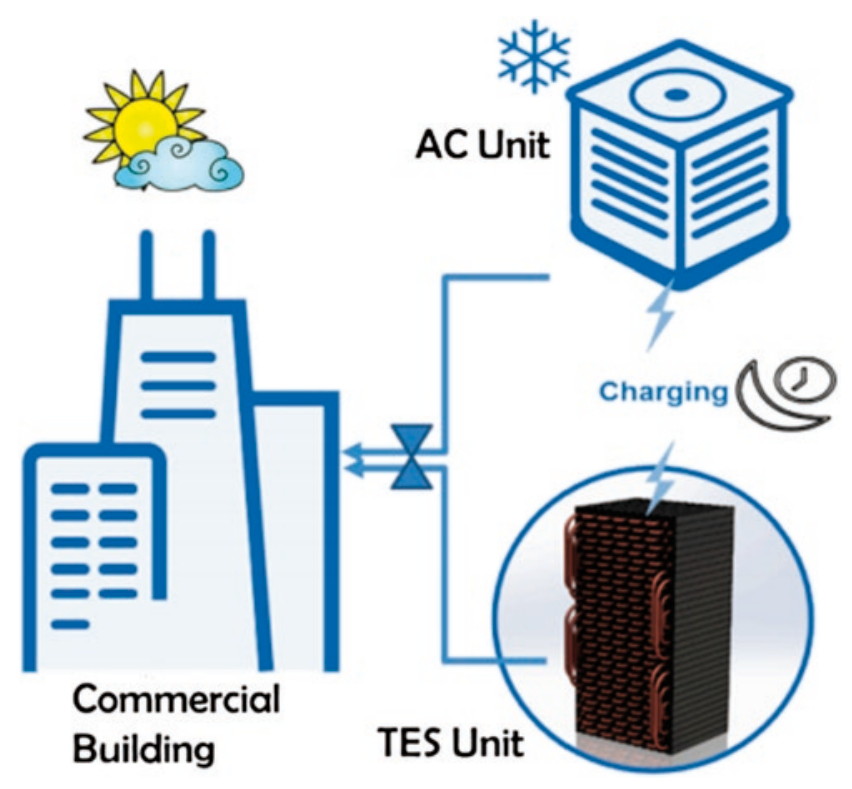

Figure 13. PCC TES System with single refrigeration cycle.

the longest system duration (240 min or C/4 rate) (Fig. 15). Given the utility rate structure with high demand charge costs, batteries' greatest value was reducing demand charges and not offsetting energy to lower the time of use periods (arbitrage). Shorter duration systems minimized payback period because typical load profiles have a non-linear relationship between reduction in peak power and required energy (Fig. 15).

\section{Simulation discussion}

At $\$ 300 / \mathrm{kW}$ and $\$ 300 / \mathrm{kW}$ h, payback periods below 5 years and as low as 3 years make battery energy storage a compelling technology for many commercial/industrial buildings. Businesses might opt for larger battery systems where the payback period is longer but the total utility bill savings are higher. Current commercial energy storage systems were compared against NREL's simulated energy storage systems by computing their cost if NREL's cost factors applied: $\$ 300 / \mathrm{kW}$ and $\$ 300 / \mathrm{kW}$ h. These two normalizations were combined into a single, energy normalized cost, $C_{\text {simulated, }}$ by multiplying the system's C-rate by the power normalized cost $(\$ 300 / \mathrm{kW})$ and adding it to the energy normalized cost $(\$ 300 / \mathrm{kW} \mathrm{h})$.

$$
C_{\text {simulated }}=\frac{\$ 300}{\mathrm{~kW} \mathrm{~h}}+\frac{\$ 300}{\mathrm{~kW}} \times C-\text { rate. }
$$

The actual cost of commercial energy systems was then compared against what the system costs under NREL's normalizations to see if current ES systems can provide the demand charge reduction value predicted by NREL (Table 9). It is important to note here that only a select few current commercial ES systems were evaluated to show the current economic viability of energy storage systems with NREL's published demand charge reduction model. Equation (1) and the method described here can be applied to other or new energy storage systems with different cell technologies to evaluate if they can provide $<5$ years payback periods in demand charge reduction alone (Table 10).

Tesla's Powerwall 2 exceed the costs simulated in the NREL study that concluded a longer payback period for these low power systems. The demand charge reductions of high power systems, like LG RESU 10, already meet the battery costs simulated and deliver the lowest payback period. However, no commercial system was found that could deliver $2 \mathrm{C}$ rates, the lowest payback period system simulated. Based on these results, there is high economic potential for small energy storage systems with high power capability; however, these systems have more challenging safety considerations. ${ }^{25}$ 
Table 8. Battery pack type comparison.

\begin{tabular}{l|c|c|c}
\hline \multicolumn{2}{c}{ Lead acid VRLA } & Lithium ion NCM & Future lithium ion (estimated) \\
\hline Cell energy cost $(\$ / \mathrm{kW} \mathrm{h})$ & 100 & $200-500^{26}$ & $150-200$ \\
\hline Specific energy $(\mathrm{W} \mathrm{h} / \mathrm{kg})$ & 40 & 150 & 200 \\
\hline Cycle life & 1000 at $50 \%$ D0D & 1900 at $80 \% \mathrm{DOD}$ & N/A \\
\hline Discharge time & $\mathrm{C} / 4$ & $1 \mathrm{C}$ & $\mathrm{N} / \mathrm{A}$ \\
\hline Efficiency & 0.8 @ $4 \mathrm{~h}$ rate & $0.99 @ 4 \mathrm{~h}$ rate & N/A \\
\hline
\end{tabular}

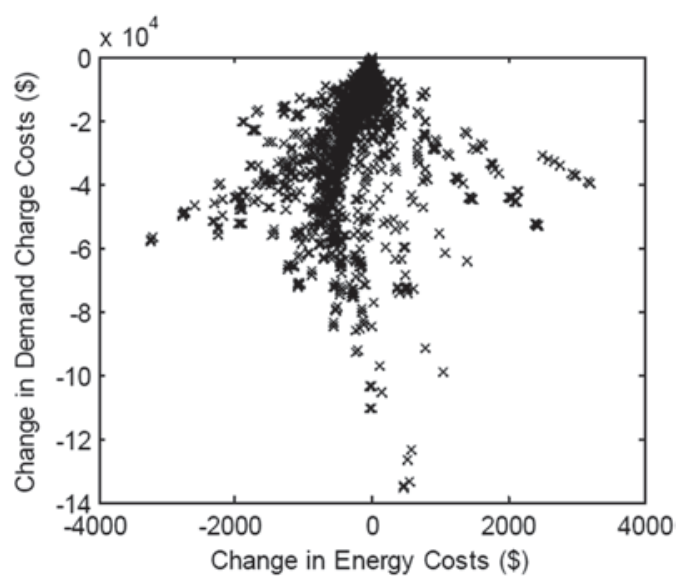

Figure 14. Impact of battery operation on energy costs and demand charge costs for all simulated load cases, Source: Neubauer, Jeremy, and Mike Simpson. Deployment of behind-the-meter energy storage for demand charge reduction. No. NREL/TP-5400-63162. National Renewable Energy Lab. (NREL), Golden, C0 (United States), 2015. Reprinted with permission from the National Renewable Energy Laboratory, from https://www.nrel.gov/ docs/fy15osti/63162.pdf, accessed August 25, 2017.61

\section{TES cooling cost}

The electrical energy normalized cost for an IceBear TES cooling system was calculated to compare with a battery system cost. IceEnergy estimated the installed cost to a private sector customer for an Ice Bear 30 ton hour (105 kW h) system and a 5-ton (17.5 kW) A/C unit was about $\$ 25,000 .{ }^{62,63}$ To isolate the cost of the IceBear TES system, the replacement cost for a 5-ton A/C unit was subtracted from the total installed cost. NREL's National Residential Efficiency Measures Database gave the average cost to replace a 5 ton AC unit with a 24.5 Seasonal Energy Efficiency Ratio (SEER) at $\$ 11,000 .{ }^{64}$ Air conditioners cycle heat between two temperature reservoirs (building and outside) and therefore deliver greater cooling power than the input electric power by a factor known as the coefficient of performance (C.O.P.). ${ }^{65}$ This SEER corresponded to a C.O.P. value of 4.5 , which means one watt of electricity provided $4.5 \mathrm{~W}$ of cooling.
Since a battery input and output is electrical energy, a battery system that can deliver the same performance as a TES system has an energy capacity equal to the TES capacity divided by the air conditioner's C.O.P. For example, the TES system above which has a C.O.P. of 4.5 , a $23 \mathrm{~kW} \mathrm{~h}$ battery stores the same energy as a $105 \mathrm{~kW}$ h IceBear TES cooling system with a $\mathrm{C} / 3$ discharge rate since the IceBear peak cooling power is $35 \mathrm{~kW}$. The electrical energy normalized cost for the IceBear 30 is $\$ 600 / \mathrm{kW}$ h with a $\mathrm{C} / 3$ rate. This is more expensive than the current battery storage options and TES cooling is limited to demand charge reduction during summer months when air conditioning makes up a large proportion of peak electricity use.

\section{Conclusion}

Energy storage technologies can reduce demand charges for commercial and industrial customers as well as residential customers as demand charges for residential customers are growing. While mechanical energy storage technologies like pumped hydro dominate the total energy storage capacity, such technologies are too large and geographically dependent for use in behind the meter applications. Instead chemical devices like batteries and thermal devices like water heaters or ice storage have the greatest potential for demand charge reduction.

Battery storage is more flexible than TES because it can power any device that uses electricity. Lead acid is a mature battery technology with low initial capital cost; however, poor efficiency at high C-rates and low cycle life with high DOD lead to larger lifecycle costs than high initial cost lithium-ion batteries. Future lithium ion battery chemistries that use varied materials for the anode and cathode could increase the energy density by $50-100 \%$. Battery chemistries that can solve the lifetime and safety issues pure lithium anodes could result in batteries with $10 \times$ the energy density of today's cells and dominate the energy storage market.

The materials required for TES are less expensive and last longer than electrochemical batteries; however, the technology is limited to building climate control and cannot power other devices. Water is the most common and least expensive storage material used in both hot water heating for space heating storage and ice makers for space cooling storage. However, ice has low thermal conductivity and phase change composite materials, 

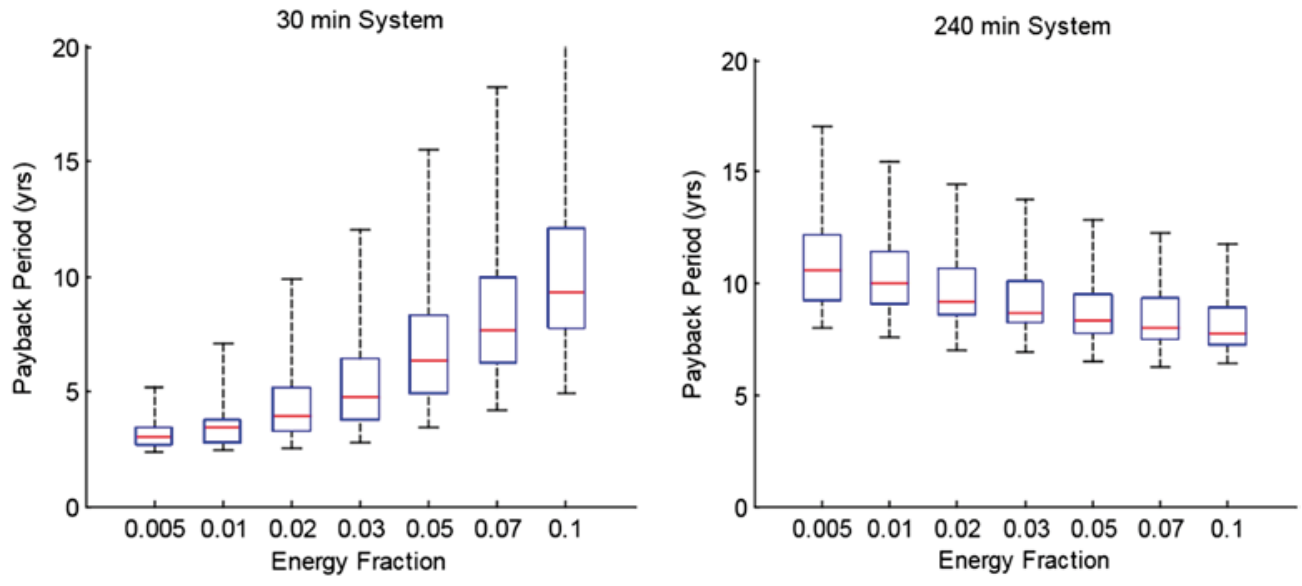

Figure 15. Payback period for battery systems as a function of energy fraction and power. The battery energy required to eliminate all variability in building load was calculated and different energy fractions from this total were modeled $(0.005,0.01$, etc). The plot on the left were high power battery systems simulated to discharge completely in 30 min while the plot on the right fully discharged in $240 \mathrm{~min}$. Each box plot shows the minimum, 25th percentile, median, 75th percentile and maximum payback period across all 98 facilities modeled in the NREL study, Source: Neubauer, Jeremy, and Mike Simpson. Deployment of behind-the-meter energy storage for demand charge reduction. No. NREL/TP-5400-63162. National Renewable Energy Lab. (NREL), Golden, C0 (United States), 2015. Reprinted with permission from the National Renewable Energy Laboratory, from https://www.nrel.gov/docs/fy15osti/63162.pdf, accessed August 25, 2017.61

Table 9. Energy and power ratings of battery systems for BLAST simulation.

\begin{tabular}{l|c} 
Available energy fractions & $\begin{array}{c}0.5 \%, 1 \%, 2 \%, 3 \%, 5 \%, 7 \%, \\
\text { and } 10 \% \text { of } E_{\max }\end{array}$ \\
\hline Battery duration & $30,40,60,120$, and 240 min \\
\hline
\end{tabular}

like graphite encapsulated wax, compromise latent heat for greater thermal conductivity and can equal storage densities of high power ice/copper systems.

Simulations with real building load profiles performed by NREL show that battery storage systems can have payback periods below 5 years in most building surveyed; however, only with high demand charges like SCE summer on-peak rate: $\sim 30 \$ / \mathrm{kW}$. Fast discharge rates increase the value of ES systems for demand charge reduction and current high power commercial lithium ion battery storage marketed toward industrial and commercial customers already meet the systems cost simulated in the NREL model. IceBear was the only current commercial TES cooling system marketed to businesses for demand charge reduction and when costs were translated to NREL's battery model, the product was not competitive with battery storage. Innovation in both battery cell and TES materials is active; however, lithium ion batteries have a larger potential for performance increases.

\section{Glossary of terms}

Anode: The negatively charged electrode in a battery.

Arbitrage: Economic benefit from buying electricity during low price periods, storing energy, and then selling electricity during high price periods.

Behind the meter: Energy storage installations owned and operated by utility customers.

Cathode: The positively charged electrode in a battery.

Chemical storage: Energy stored in chemical bonds. Batteries are chemical storage devices that use electrical energy to create chemical bonds and establish a chemical potential difference.

Coefficient of performance: The thermal energy produced by an air conditioner divided by the input electrical energy. Coefficient of performance is often greater than 1 as an air conditioner moves thermal energy between two temperature

Table 10. Commercial battery system costs compared with NREL simulation.

\begin{tabular}{|c|c|c|c|c|}
\hline Vendor & C-rate & NREL simulation cost, $C_{\text {Simulated }}(\$ / \mathrm{kW} \mathrm{h})$ & Real cost $(\$ / k W h)$ & Required cost change \% \\
\hline Tesla powerwall 2 & $\mathrm{C} / 4$ & 375 & 465 & -20 \\
\hline LG RESU 10 & $1.4 \mathrm{C}$ & 720 & 630 & +14 \\
\hline AllCell & $1.6 \mathrm{C}$ & 780 & 1000 & -22 \\
\hline
\end{tabular}


reservoirs which is a less entropic process than electrical charge transfer on an energy normalized basis.

C-rate: The inverse of the time in hours it takes to discharge an energy storage device. For example, a 2 C energy device takes $1 / 2 \mathrm{~h}$ to discharge or $30 \mathrm{~min}$.

Demand charge: Electric utility cost applied to a customer based on their maximum power used over a billing cycle.

Depth of discharge: The energy discharged as a percentage of the total energy stored.

Electrolyte: Medium in between the anode and cathode with charge carriers that complete the battery circuit.

Energy charge: Electric utility cost applied to a customer based on their electrical energy usage over a billing cycle.

Energy storage device: An engineered system that can store energy.

In front of the meter: Energy storage installations owned and operated by the utility.

Inverter: Power electronics hardware that converts direct current from a battery to alternating current for the grid.

Lifetime: How many years or cycles an energy storage device can operate without significant performance degradation.

Peak shaving: Discharging energy storage device during periods of high power demand to reduce grid power usage and reduce demand charge.

Phase change material: A material that changes phase (solid, liquid, gas) when heated or cooled in a thermal energy storage device.

Ramp rate: The rate of increase in power production of an energy storage or generation device.

Roundtrip efficiency: The electrical energy discharged from a storage device divided by the electrical energy required to charge the storage device.

Self-discharge: The energy lost from an energy storage device when it is charged or at a higher energy potential yet is not discharging energy.

Specific energy: The energy storage capacity of an energy storage device divided by its mass.

Specific power: The power capacity of an energy storage device divided by its mass.

Thermal runaway: Most relevant to lithium ion batteries, it is where heat from an exothermic reaction increases the reaction rate causing further heating that eventually violently destroys the battery.

Thermal storage: Energy stored by heating or cooling a substance. If the substance changes phase (water to ice), it is latent thermal storage. If the substance changes temperature, it is sensible thermal storage.

Time of use rate: Electricity price that depends on what time the electricity is used.

\section{Acknowledgment}

This work was supported as part of the Joint Center for Energy Storage Research (JCESR), an Energy Innovation Hub funded by the US Department of Energy, Office of Science, Basic Energy Sciences.

\section{REFERENCES:}

1. Booth W.: Variability in electricity demand highlights potential roles for electricity storage. Energy Inf. Agency (2013). Available at: https://www. eia.gov/todayinenergy/detail.php?id=13131\# (accessed February 2, 2017).

2. Lazar J. and Baldwin X.: Valuing the Contribution of Energy Efficiency to Avoided Marginal Line Losses and Reserve Requirements. Regulatory Assistance Project Report (2011). Available at: http://www.raponline.org/ wp-content/uploads/2016/05/rap-lazar-eeandlinelosses-2011-08-17.pdf (accessed January 30, 2018).

3. Lazard: Lazard's levelized cost of energy analysis-version 8.0 (2014). Available at: https://www.lazard.com/media/1777/levelized_cost_of_ energy_-_version_80.pdf (access January 30, 2018).

4. Denholm P., Jorgenson J., Jenkin T., Palchak D., Kirby B., Malley M.O., Hummon M., and Ma O.: The value of energy storage for grid applications. National Renewable Energy Laboratory (US). Technical Report NREL/ TP-6A20-58465. (2013). doi: NREL/TP-6A20-58465.

5. Marcy C.: Today in Energy, Nonhydro Electr. Storage Increasing as New Policies are Implemented (2015). Available at: https://www.eia.gov/ todayinenergy/detail.php?id=20652 (accessed August 13, 2017).

6. Sioshansi R., Madaeni S.H., and Denholm P.: A dynamic programming approach to estimate the capacity value of energy storage. IEEE Trans. Power Syst. 29, 395-403 (2014).

7. Walawalkar R., Apt J., and Mancini R.: Economics of electric energy storage for energy arbitrage and regulation in New York. Energy Policy 35 , 2558-2568 (2007).

8. Flynn P.C. and Cabral E.A.: The economics of energy storage in 14 deregulated power markets. Energy Stud. Rev. 14, 131-152 (2006).

9. Sioshansi R. and Denholm P.: The value of plug-in hybrid electric vehicles as grid resources. Energy J. 31, 1-24 (2010).

10. Byrne R.H. and Silva-Monroy C.A.: Estimating the Maximum Potential Revenue for Grid Connected Electricity Storage: Arbitrage and Regulation. Sandia National Laboratories (Albuquerque, New Mexico). Report SAND2012-3863 (2012), 64.

11. Nrel B.K.: Increases Value Through Optimized Ancillary Service (AS) Provision: Pumped Storage Generator Example. In Energy Storage Management for VG Integration. National Renewable Energy Laboratory (US). Presentation. (2011).

12. Drury E., Denholm P., and Sioshansi R.: The value of compressed air energy storage in energy and reserve Markets.pdf. Energy 36, 4959-4973 (2011).

13. Ong S., Campbell C., Clark N., Ong S., Campbell C., and Clark N.: Impacts of Regional Electricity Prices and Building Type on the Economics of Commercial Photovoltaic Systems Impacts of Regional Electricity Prices and Building Type on the Economics of Commercial Photovoltaic Systems. National Renewable Energy Laboratory (US). Technical Report NREL/ TP-6A20-56461 (2012).

14. General Service-Industrial Rate Schedules: Southern California Edison (2016). Available at: https://www.sce.com/wps/portal/home/regulatory/ tariff-books/rates-pricing-choices/business-rates/!ut/p/b1/ tVFNU8IwFPwtHjhm8kpKP46VOrVVVETGthemDUmJQILawKi _3qAcHEdEDub0krdvs28XlzjHpaJbWVMjtaLL3b 30ZlkaR07i9tPEz2KI7mI_nt57jnvlWEBhAXDgRHBs_ hGXuGTKNGaBi47xGdPKc (accessed May 2, 2017).

15. Wang Y. and Li L.: Time-of-use electricity pricing for industrial customers: A survey of U.S. utilities. Appl. Energy 149, 89-103 (2015).

16. Lehrman M.: Are Residential Demand Charges the Next Big Thing in Electricity Rate Design? RMI Outlet (2015). Available at: http://blog.rmi. org/blog_2015_05_21_residential_demand_charges_next_big_thing_in electricity_rate_design (accessed January 15, 2017).

17. Electric Reliability Council of Texas, 2015 Acutal Load Profiles: Backcasted Load Profiles-Hist. (n.d.). Available at: http://www.ercot.com/mktinfo/ loadprofile/alp (accessed November 9, 2016).

18. 2012 Commercial Energy Consumption Data, EnerNOC (2013). Available at: https://open-enernoc-data.s3.amazonaws.com/anon/index.html (accessed December 20, 2016). 
19. Bayram I.S. and Ustun T.S.: A survey on behind the meter energy management systems in smart grid. Renew. Sust. Energ. Rev. 72, 1-25 (2016). doi: 10.1016/j.rser.2016.10.034.

20. Munsell M.: Grid-Scale Energy Storage Balance-of-System Costs Will Decline $41 \%$ by 2020 , GreenTech Media (2016). Available at: https:// www.greentechmedia.com/articles/read/grid-scale-energy-storagebalance-of-systems-costs-will-decline-41-by-2020 (accessed June 25, 2017).

21. Kutney P., Schoen C., and Yi R.: Distributed Solar-Plus-Storage C\&I Feasibility Analysis for California-based University, 2017 NRG Energy Case Study (2017). Available at: http://www.economist.com/sites/default/files/ mit_nrg_case_study_report.vff_.pdf (accessed August 12, 2017).

22. Whittingham M.S.: Lithium batteries and cathode materials. Chem. Rev. 104, 4271-4302 (2004).

23. Li K. and Tseng K.J.: Energy efficiency of lithium-ion battery used as energy storage devices in micro-grid. In IECON 2015-41st Annual Conference of the IEEE Industrial Electronics Society (2015); pp. 5235-5240. doi: 10.1109/ IECON.2015.7392923.

24. Manuel W.G.: Energy Storage Study 2014 (2014). Available at: http:// www.energy.ca.gov/assessments/ab2514_reports/Turlock_Irrigation_ District/2014-10-28_Turlock_Irrigation_District_Energy_Storage_ Study.pdf (accessed February 5, 2017).

25. Al-Hallaj S., Wilke S., and Schweitzer B.: Energy Storage Systems for Smart Grid Applications. In Water, Energy \& Food Sustainability in the Middle East: The Sustainability Triangle, Badran A., Murad S., Baydoun E., and Daghir N., eds. (Springer International Publishing AG, Cham, Switzerland, 2014), pp. 161-192.

26. Albright G., Edie J., and Al-Hallaj S.: A Comparison of Lead Acid to Lithium-ion in Stationary Storage Applications (AllCell Technologies LLC, 2012); pp. 1-14.

27. Bhatia A.: Battery Room Ventilation and Safety. Continuing Education and Development, Inc., Course No: M05-021.

28. Housecroft C.E. and Constable E.C.: Chemistry: An Introduction to Organic, Inorganic and Physical Chemistry, 4th Edition (Pearson Education, Upper Saddle River, New Jersey, 2010).

29. B. University: Types of Lithium Ion (2017). Available at: http:// batteryuniversity.com/learn/article/types_of_lithium_ion (accessed August 29, 2017).

30. Guo Y.G., Hu J.S., and Wan L.J.: Nanostructured materials for electrochemical energy conversion and storage devices. Adv. Mater. 20, 2878-2887 (2008).

31. Julien C.M., Mauger A., Zaghib K., and Groult H.: Comparative issues of cathode materials for Li-ion batteries. Inorganics 2, 132-154 (2014).

32. Environ E., Etacheri V., Marom R., Elazari R., Salitra G., and Aurbach D.: Challenges in the development of advanced Li-ion batteries: A review. Energy Environ. Sci. 4, 3243-3262 (2011)

33. Fehrenbacher K.: Why Tesla's grid batteries will use two different chemistries. Fortune (2015). Available at: http://fortune.com/2015/05/18/ tesla-grid-batteries-chemistry/ (accessed August 29, 2017).

34. Williard N., He W., Hendricks C., and Pecht M.: Lessons learned from the 787 dreamliner issue on lithium-ion battery reliability. Energies 6, 4682-4695 (2013).

35. Takahara K.: Sony's Battery Fiasco a Symptom of Bigger Woes at Legendary Firm, McClatchy-Trib. Bus. News, 2006 (n.d.). Available at: http://www.japantimes.co.jp/news/2006/10/12/business/sonys-batteryfiasco-a-symptom-of-bigger-woes-at-legendary-firm/\#.WHk1XfkrLcs (accessed January 21, 2017).

36. Schweitzer B., Wilke S., Khateeb S., and Al-Hallaj S.: Experimental validation of a $0-D$ numerical model for phase change thermal management systems in lithium-ion batteries. J. Power Sources 287, 211-219 (2015).

37. Kizilel R., Sabbah R., Selman J.R., and Al-Hallaj S.: An alternative cooling system to enhance the safety of Li-ion battery packs. J. Power Sources 194 , 1105-1112 (2009).

38. Amarakoon S., Smith J., and Segal B.: Application of life-cycle assessment to nanoscale technology: Lithium-ion batteries for electric vehicles.
Design for the Environment Program, EPA's Office of Pollution Prevention and Toxics. EPA 744-R-12-001 (2013).

39. Boyden A., Soo V.K., and Doolan M.: The environmental impacts of recycling portable lithium-ion batteries. Procedia CIRP 48, 188-193 (2016).

40. B. University: Bu-308: Availability of Lithium (2017). Available at: http:// batteryuniversity.com/learn/article/availability_of_lithium (accessed August 21, 2017).

41. Wu H. and Cui Y.: Designing nanostructured Si anodes for high energy lithium ion batteries. Nano Today 7, 414-429 (2012).

42. Takada K.: Progress and prospective of solid-state lithium batteries. Acta Mater. 61, 759-770 (2013).

43. Manthiram A.: Materials challenges and opportunities of lithium ion batteries. J. Phys. Chem. Lett. 2, 176-184 (2011).

44. Bruce P.G., Freunberger S.A., Hardwick L.J., and Tarascon J-M.: Li-O 2 and Li-S batteries with high energy storage. Nat. Mater. 11, 19-29 (2012).

45. Crabtree G., Kócs E., and Trahey L.: The energy-storage frontier: Lithium-ion batteries and beyond. MRS Bull. 40, 1067-1078 (2015).

46. Albright G., Edie J., and Al-Hallaj S.: A Comparison of Lead Acid to Lithium-Ion in Stationary Storage Applications (AllCell Technologies LLC, 2012).

47. Michaels J.: 2012 Commercial Buildings Energy Consumption Survey: Energy Usage Summary (2012). Available at: http://www.eia.gov/ consumption/commercial/reports/2012/energyusage/index.php (accessed November 3, 2016).

48. Willis R. and Parsonnet B.: Energy efficient TES designs for commercial DX systems. ASHRAE Transactions116, 147-156 (2010).

49. Keep It Cool with Thermal Energy Storage (1995). Available at: http:// www.nrel.gov/docs/legosti/old/20176.pdf (accessed November 5, 2016).

50. Miller G. and Energy I.: Small thermal energy storage and its role in our clean energy future. In Summer Study on Energy Efficiency in Buildings (2016); pp. 1-12.

51. Lazar J.: Teaching the "Duck" to Fly, Regulatory Assistance Project Webinar (2014).

52. Denholm P., Ong S., and Booten C.: Using Utility Load Data to Estimate Demand for Space Cooling and Potential for Shiftable Loads, National Renewable Energy Laboratory (US), Technical Report NREL/TP-6A2054509 (2012), doi: 10.2172/1046314.

53. Pacific Gas \& Electric Company: Thermal Energy Storage Strategies for Commercial HVAC Systems. Application Note (1997).

54. De Gracia A. and Cabeza L.F.: Phase change materials and thermal energy storage for buildings. Energy Build 103, 414-419 (2015).

55. Pincemin S., Olives R., Py X., and Christ M.: Highly conductive composites made of phase change materials and graphite for thermal storage. Sol. Energy Mater. Sol. Cells 92, 603-613 (2008).

56. Razack S.A.K., Bhaskar M., Shabtay Y., Stilman H., Al-hallaj S., and Avenue M.: Design and performance of thermal energy storage module using high thermal conductivity phase change composite material. In Int. Compress. Eng. Refrig. Air Cond. High Perform. Build. Conf. (2016).

57. Boston T.: 2014-04-07 Letter from PJM Interconnection to DOE Deputy Assistant Secretary, Dr. Kathleen Hogan (2014), 1-2. Available at: https:// www.regulations.gov/document?D=EERE-2012-BT-STD-0022-0302 (accessed January 9, 2017).

58. Podorson D.: Battery Killers: How Water Heaters Have Evolved into Grid-Scale Energy-Storage Devices. An E Source White Paper (2014). Available at https://www.esource.com/ES-WP-18/GIWHs (accessed January 31, 2018).

59. Kepplinger P., Huber G., and Petrasch J.: Field testing of demand side management via autonomous optimal control of a domestic hot water heater. Energy Build 127, 730-735 (2016).

60. Neubauer J.: Battery Lifetime Analysis and Simulation Tool (BLAST) Documentation. National Renewable Energy Laboratory (US), 
Technical Report NREL/TP-5400-63246 (2014). doi: NREL/ TP-5400-63246.

61. Neubauer J. and Simpson M.: Deployment of Behind-the-Meter Energy Storage for Demand Charge Reduction. National Renewable Energy Laboratory (US), Technical Report NREL/TP-5400-63162 (2015).

62. Trabish H.: Ice, ice energy: The hot market for cooled liquid energy storage, Util. Drive (2015). Available at: http://www.utilitydive.com/ news/ice-ice-energy-the-hot-market-for-cooled-liquid-energystorage/408356/ (accessed May 1, 2017).
63. IceEnergy, IceBear30 Product Sheet (n.d.). Available at: https://www. ice-energy.com/wp-content/uploads/2016/03/ICE-BEAR-30-ProductSheet.pdf (accessed April 21, 2017).

64. National Residential Efficiency Measures Database, Natl. Renew. Energy Lab. (2012). Available at: http://www.nrel.gov/ap/retrofits/measures. cfm?gId=2\&ctId=375 (accessed December 8, 2016).

65. Moran M.J.: Engineering thermodynamics. In CRC Handbook of Mechanical Engineering, 2nd ed., Kreith F. and Goswami D.Y., eds. (CRC Press, Baton Rouge, Florida, 2004). 